\title{
Associations of head circumference at birth with early- life school performance and later-life occupational prestige
}

\author{
Serhiy Dekhtyar - Department of Clinical Neuroscience, Section of Psychology, Karolinska Institutet, \\ Stockholm, Sweden \\ serhiy.dekhtyar@ki.se \\ Hui-Xin Wang - Aging Research Center, Department of Neurobiology, Care Sciences and Society, \\ Karolinska Institutet and Stockholm University, Sweden \\ Kirk Scott - Centre for Economic Demography and Department of Economic History, Lund \\ University and Stockholm University Demography Unit, Sweden \\ Anna Goodman - Faculty of Epidemiology and Population Health, London School of Hygiene and Tropical \\ Medicine, UK \\ Ilona Koupil - Centre for Health and Equity Studies, Stockholm University/Karolinska Institutet, \\ Sweden \\ Agneta Herlitz - Department of Clinical Neuroscience, Section of Psychology, Karolinska Institutet, \\ Sweden
}

(Received May 2014 Revised November 2014)

http://dx.doi.org/10.14301/Ilcs.v6i1.308

\section{Abstract}

Head circumference at birth has been suggested as a marker of foetal brain development. New-borns with small head size have been shown to have lower intelligence scores in childhood. It is, however, unclear whether this relationship extends into adult life, and more importantly, whether adult status attainment and lifetime success is affected as a result. Furthermore it is unclear how social origin at birth attenuates the relationship between foetal brain development, childhood cognitive outcomes, and lifetime status attainment. Using the Uppsala Birth Cohort Multigenerational Study, a unique population-based database of 14,192 individuals followed from birth into advanced old age, we demonstrate that those born with small head circumference experience reductions in both early-life school performance and lifetime occupational prestige. These effects are not subject to modification by parental social class: small head size at birth is associated with lower grades and lower occupational prestige among individuals born into both advantaged and disadvantaged social classes. Employing causal mediation analysis, we also demonstrate that the link between head circumference at birth and adult occupational prestige is mainly the result of a direct effect, although a portion of this effect is also mediated by early-life school performance which also contributes to occupational attainment trajectories. These findings demonstrate the importance of early-life environments for cognitive development as well as lifetime status attainment.

Keywords: head circumference, brain development, childhood cognitive ability, school grades, life-time occupational prestige, life-course, Sweden, population-based, longitudinal 


\section{Introduction}

The foundations for brain development are laid down during the foetal stage of life. At birth, brain volume is about a third of the healthy adult brain volume (Holland et al., 2014). Measures of head size at birth, such as bi-parietal diameter or head circumference $(\mathrm{HC})$, are widely used in assessing foetal growth, dating pregnancies, and in the detection of foetal abnormalities (Chitty, Altman, Henderson, \& Campbell, 1994). The correlation between clinically measured $\mathrm{HC}$ and total brain volume is considerable ( $r=0.55$, (Lindley, Benson, Grimes, Cole, \& Herman, 1999)), allowing birth head circumference to be considered a marker of in-utero brain development (Cooke, Lucas, Yudkin, \& Pryse-Davies, 1977). Foetal brain development affects postnatal cognitive outcomes (Webb, Monk, \& Nelson, 2001) and several studies in children have shown that those born with smaller brains, as indicated by low $\mathrm{HC}$ at birth, also have lower scores on cognitive tests in early life, with the effect discernible even among babies born within the normal range of birth size (Broekman et al., 2009; Gale et al., 2006; Heinonen et al., 2008).

Whereas extensive previous literature has explored the long-term effects of gestational age or birth-weight (Black, Devereux, \& Salvanes, 2007; Moster, Lie, \& Markestad, 2008; Richards, Hardy, Kuh, \& Wadsworth, 2001), studies on the long-term effects of birth HC are few and often report conflicting results. An association between biparietal diameter at birth and IQ in 48-74 year-olds has been reported, although $\mathrm{HC}$ at birth was not associated with intelligence scores in the same individuals (Martyn, Gale, Sayer, \& Fall, 1996). Additionally, $\mathrm{HC}$ at birth was not related to either general cognitive ability or logical memory in midto late-life (Gale, Walton, \& Martyn, 2003; Zhang et al., 2009). However, a recent study demonstrated that $\mathrm{HC}$ at birth, together with other measures of birth characteristics, predicted cognitive outcomes among 68 year-old men (Raikkonen et al., 2013). Whether an association between birth $\mathrm{HC}$ and adult cognitive outcomes in fact translates into real-life success, such as adult status attainment or occupational prestige, has not yet been investigated.

Extensive previous literature has also indicated that parental socioeconomic status is a predictor of cognitive outcome in childhood (Bradley \& Corwyn, 2002; Duncan, Brooks-Gunn, \& Klebanov, 1994), and it is also associated with various indicators of later-life status attainment and success (Deary et al., 2005; Fischer et al., 1996). Although previous studies interested in the long-term effects of foetal development have also integrated measures of early socioeconomic status, this has generally been limited to an attempt to control for possible confounding effects of social origin (Matte, Bresnahan, Begg, \& Susser, 2001; Richards, Hardy, Kuh, \& Wadsworth, 2002; Silva, Metha, \& O'Callaghan, 2006). It has largely been overlooked that brain development takes place within a socioeconomic context (Hackman, Farah, \& Meaney, 2010), and that biological effects can manifest themselves differently depending on the social environment surrounding development. For example, previous research in Sweden has reported that preterm birth is related to poorer school achievement among children whose parents have low levels of education; among children of more highly educated parents, preterm birth has a much more limited detrimental effect (Gisselmann, Koupil, \& De Stavola, 2011). On the other hand, two studies have reported no evidence of effect modification by social class in relation to the association between birth weight and subsequent cognitive outcomes (Jefferis, Power, \& Hertzman, 2002; Matte et al., 2001). To our knowledge, no previous research has examined the issue of effect modification by social class in relation to head size at birth and subsequent cognitive or human capital outcomes.

To date, no study has examined whether birth $\mathrm{HC}$ is associated with childhood cognitive ability as well as adult status attainment over the life course of the same cohort. By introducing adult status attainment into a life-course model it becomes possible to examine how prerequisites for human capital accumulation (childhood cognitive ability) are leveraged into the outcomes of human capital accumulation (adult status attainment or prestige) and how this process is affected by an indicator of in-utero development of the brain (birth $\mathrm{HC}$ ). Furthermore, it is unclear from previous literature what role social class of origin plays in the relationship between foetal brain development and later-life outcomes. In this paper we investigate whether in-utero brain development, measured by $\mathrm{HC}$ at birth, affects (i) school grades reported at age 9-10 and (ii) later-life status attainment captured by occupational prestige, in the same individuals 
followed-up over the life course. We assess both direct and indirect effects, as well as explicitly test whether social origin is a confounder, or rather an effect modifier, for the link between HC at birth, school grades in childhood, and later-life status attainment (see Figure 1 for conceptual framework). These questions are examined using a unique population-based database, the Uppsala Birth Cohort Multigenerational Study, which combines high-quality Swedish register data with manually-collected archival information on individuals followed from birth until 80-94 years (Koupil, 2007).

Figure 1. Conceptual framework of the study

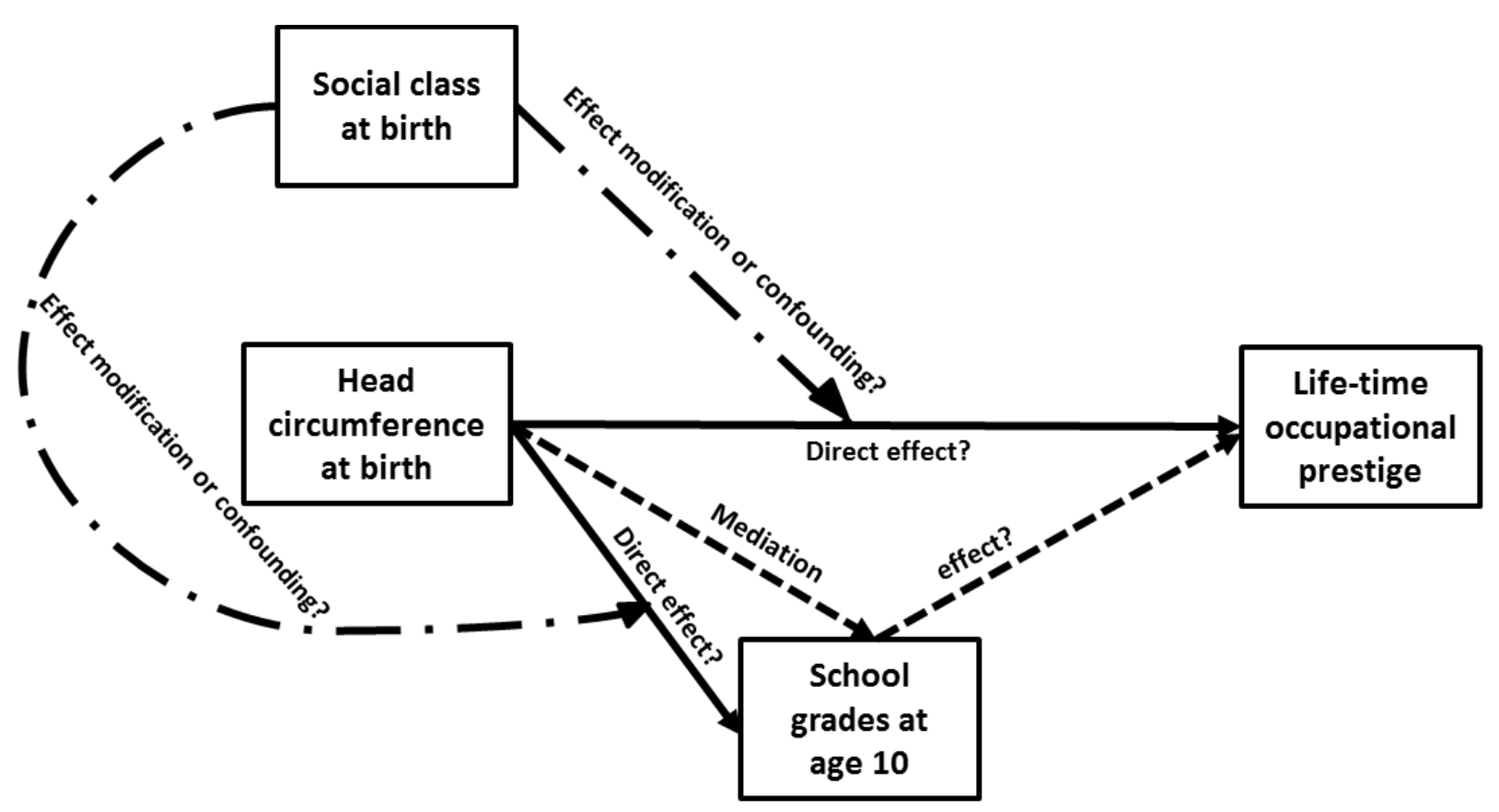

\section{Methods}

\section{Study population}

The Uppsala Birth Cohort Multigenerational Study (UBCOS) comprises all live births at the Uppsala University Hospital between 1915 and 1929 , which accounted for an estimated $75 \%$ of births in the city of Uppsala and $50 \%$ of births in surrounding rural parishes (Goodman \& Koupil, 2012). The study was approved by a Regional Ethics Committee in Stockholm, Sweden. This population has previously been shown to be broadly representative of the Swedish population during that historical period in terms of infant mortality and subsequent fertility (Goodman \& Koupil, 2009,
2012). From a total of 14,192 births, 13,811 were successfully traced through parish archives until death, emigration or until being assigned a personal identification number in 1947. Of these, 12,168 were alive and resident in Sweden in 1960, constituting the population assessed for eligibility, for whom record linkage provided detailed information over their lives. After excluding those who did not meet our inclusion criteria, or who had missing data, our analysis population amounted to 6,024 individuals (Figure 2). 
Figure 2. Study population flow

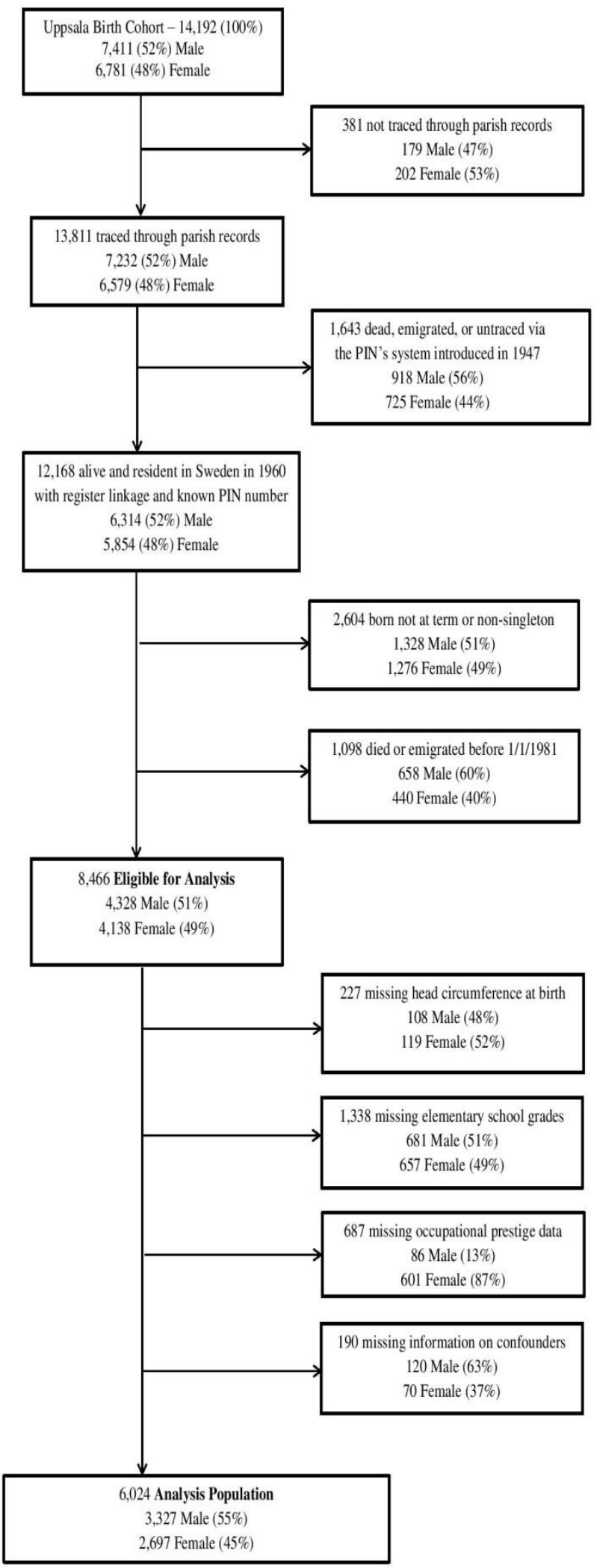




\section{Head circumference at birth}

We were interested in the effects of in-utero brain development within the normal range of deliveries, and therefore restricted our sample to term, singleton babies. As a result, we excluded multiple births $(\mathrm{N}=293)$, pregnancies lasting less than 37 weeks $(\mathrm{N}=678)$ or more than 41 weeks $(\mathrm{N}=1,274)$, as well as unknown gestation durations $(\mathrm{N}=359)$.

We used occipito-frontal circumference as our measure of head circumference as this has been previously shown to be an appropriate index of brain weight among infants (Cooke et al., 1977), but also because occipito-frontal measurements were collected for the entire UBCoS population over the study period of 1915-1929. Measurements of biparietal diameter, another measure of foetal head growth, began in 1924 and are therefore available for only a fraction of study participants. Occipitofrontal circumference was measured to the nearest $0.1 \mathrm{~cm}$ by placing a tape measure across the most prominent part of the forehead (supraorbital ridges, usually 1-2 fingers above the eyebrows) and around the most prominent part of the back of the head (occiput). The measure indicates the largest circumference of the head. The range of $\mathrm{HC}$ in the sample of term singleton deliveries was $23-46.1 \mathrm{~cm}$. We expressed these values in terms of gestationalage-standardized Z-scores, which were then categorized into three groups to denote small gestational-age-standardized HC (STD<-1), average gestational-age-standardized $\mathrm{HC} \quad(-1 \leq \mathrm{STD} \leq 1)$, and large gestational-age-standardized $H C \quad(S T D>1)$. A continuous specification of the $\mathrm{HC}$ variable with polynomial functions was also tested, although we decided to use standard deviation cut-offs for comparability with previous literature (Gale et al., 2006). Head circumference measurements were recorded for 8,239 individuals (97\%) who passed prior inclusion criteria. On average, $\mathrm{HC}$ at birth was lower for girls than for boys, as well as for babies born into disadvantaged SES backgrounds. The correlation between gestational-age-standardized $\mathrm{HC}$ and birth weight standardized for gestational age was 0.58 .

\section{Early-life school grades}

We extracted information on grades collected during the spring term of elementary school's third year, when individuals were mostly nine or ten years old. School grades have been previously shown to be associated with cognitive ability and IQ $(r \approx .5)$ in Sweden and elsewhere (Gustafsson \& Reuterberg, 2000; Neisser et al., 1996; Rosander, Bäckström, \& Stenberg, 2011). We extracted marks from the following seven subjects: arithmetic and geometry, writing and grammar, speech and reading, Christian religion studies, handwriting, local geography and history, and workbook exercises from different subjects.

Subjects were marked using the grades $C$ (lowest), Bc, B, Ba, AB, a and A (highest), with additional qualification with pluses and minuses. We re-coded the marks from 0 (Grade C) to 18 (Grade A) in accordance with the scoring system suggested by the Swedish education authorities in 1942 (SOU, 1942). We calculated an overall third grade mean score after standardizing marks in each subject individually. Factor analysis confirmed that a single latent factor explained much of the observed variation in the marks (first Eigenvalue 3.71, second 0.79 ).

School grades were successfully obtained from the archives for 6,901 (84\%) individuals who fulfilled prior inclusion criteria. They were more likely to be untraced among children of higher socio-economic status (SES), likely reflecting weaker coverage of private schools in the dataset (Goodman, Gisselmann, \& Koupil, 2010).

\section{Lifetime status attainment - adult occupational prestige}

We measured individuals' lifetime status attainment through a prestige score associated with their longest-held occupation in adulthood. We used the Standard International Occupational Prestige Scale (SIOPS) (Ganzeboom \& Treiman, 1996), which is a continuous scale (range 6-78) that emphasizes subjective perceptions of social rewards, such as approval, respect, admiration, and contempt inherent in occupations (Rose, 2005). It is flexible with respect to national, social, and cultural settings since it was developed as a result of averaging prestige scales from 60 countries. This occupational prestige score was assigned to the most frequently reported occupation found in the censuses of 1960, 1970, and 1980. Health professionals (prestige score: 70) and higher education professionals (prestige score 60) were some of the most common high-prestige occupations in the data, whereas cleaners (prestige 
score 21) and low-level clerks (prestige score 30) were some of the most common low-prestige occupations.

Individuals with missing or unreported occupational information were excluded, amounting to $10 \%$ of those who passed prior inclusion criteria. Of the 687 with unknown occupations, women were over-represented $(87 \%)$, likely as a result of being housewives. We ran a sensitivity analysis where females with unreported occupational information were assigned a SIOPS score equivalent to an ISCO code 5121, "housekeepers and other workers" which is a paid position. Since substantive results remained unchanged we opted for not including these individuals in the final analysis to avoid misclassification. If an individual had held different positions across all three censuses (about 20\% of cases), we based their lifetime occupation on the 1970 poll (i.e., when they were $41-55$ years old), as research has demonstrated that in comparable cohorts of Swedish men and women, improvements in occupational prestige flatten out after 40 years of age (Härkönen \& Bihagen, 2011). Mortality did not bias the assignment of prestige scores due to our requirement that study subjects survive until January 1, 1981, allowing us a window of three population censuses to determine individuals' lifetime occupation.

\section{Social class at birth}

Family social class at birth was based on father's occupation if present $(80 \%)$, or mother's occupation if not (20\%). It was derived in accordance with the Swedish socioeconomic classification scheme with a category "house-daughters" added to identify unemployed single mothers living with their parents at the time of the birth of their child. We, in accordance with a previous study based on similar material (Mishra, Chiesa, Goodman, De Stavola, \& Koupil, 2013), generated a binary indicator of social origin that distinguishes between advantaged background (children of higher and intermediate non-manual workers; entrepreneurs and farmers; skilled manual workers) and disadvantaged background (low non-manual workers; unskilled production/service workers; house-daughters).

\section{Statistical analysis}

We estimated a series of progressively-adjusted ordinary least squares regressions predicting elementary school grades and lifetime occupational prestige, concluding with a fully-adjusted model that also included parental social class at birth. Sex, birth year, maternal age at childbirth, birth order, and birth weight were considered as potential confounders. We tested for interactions between $\mathrm{HC}$ and social class at birth when predicting childhood school grades as well as occupational prestige. Next, we examined the relationship between birth $\mathrm{HC}$ and school grades as well as adult occupational prestige within the levels of social origin, suspecting that social origin might be an effect modifier, rather than a confounder. We then investigated how social origin and $\mathrm{HC}$ at birth work together in shaping childhood school grades and long-term occupational prestige.

Finally, we employed mediation analysis to establish whether the relationship between birth $\mathrm{HC}$ and occupational prestige is direct or mediated via childhood school grades. A method for causal mediation analysis that builds on the counterfactual framework was applied (Imai, Keele, \& Tingley, 2010). The assumption of sequential ignorability required for identification of causal mediation was tested using a method suggested for sensitivity analysis (Imai, Keele, \& Yamamoto, 2010). Causal mediation and sensitivity analyses were conducted in STATA using the modules "medeff" and "medsens" developed by Hicks \& Tingley (2011).

\section{Results}

Of the original 14,192 UBCoS participants, 8,466 were born singleton, at term, and were alive and resident in Sweden on 1 January 1981, constituting the population eligible for analysis. Of these, 6,024 had non-missing information on head circumference, elementary school grades, occupational prestige, socioeconomic, and other background variables, making them the analysis population in the study (Figure 2). Background characteristics of the study participants are presented in Table 1 . Study subjects were more likely to be male, born to mothers aged 25-29 years, and come from non-privileged social backgrounds. Mean level of school grades as well as occupational prestige was lower in individuals coming from disadvantaged social backgrounds. Similarly, both school grades and occupational prestige averages were lowest among the subgroups of participants with small $\mathrm{HC}$ at birth. 
The final analysis population differed significantly from the 2,442 of those eligible, but excluded due to missing data on covariates, with respect to family social class at birth (e.g. $12 \%$ born to parents of higher non-manual families among those excluded vs. $8 \%$ among those included, $\mathrm{p}<0.001)$. Social class differences were largely a result of excluding individuals with missing elementary school grades due to limited coverage of private schools preferred by high-SES parents. In addition, the proportion of women was higher among the excluded 2,442 individuals $(60 \%$, vs. $45 \%$ among those included, $p<0.001$ ). This is likely a result of removing subjects with missing occupations, among whom women were overrepresented.

\section{Table 1. Baseline characteristics of the study population: Uppsala Birth Cohort Multi-generational Study $(6,024$ men and women)}

\begin{tabular}{|c|c|c|c|c|}
\hline Variable & Range/categories & Percent & Mean grades (SD) & Mean prestige (SD) \\
\hline \multicolumn{5}{|l|}{ Gender } \\
\hline & Male & $55 \%$ & $-0.11(0.72)$ & 40.6 (11.9) \\
\hline & Female & $45 \%$ & $0.12(0.73)$ & $35.3(11.1)$ \\
\hline \multicolumn{5}{|c|}{ Birth order } \\
\hline & 1 & $38 \%$ & $0.11(0.74)$ & $39.6(11.7)$ \\
\hline & $2-3$ & $38 \%$ & $0(0.71)$ & $38.3(11.8)$ \\
\hline & $4-5$ & $14 \%$ & $-0.05(0.74)$ & $37.2(11.1)$ \\
\hline & $6-16$ & $10 \%$ & $-0.08(0.73)$ & $35.1(10.2)$ \\
\hline \multicolumn{5}{|c|}{ Mother's age at birth } \\
\hline & $15-19$ & $5 \%$ & $0.02(0.77)$ & $36.8(10.3)$ \\
\hline & $20-24$ & $26 \%$ & $-0.03(0.71)$ & $37.2(11.0)$ \\
\hline & $25-29$ & $29 \%$ & $0.05(0.73)$ & 39.3 (11.9) \\
\hline & $30-34$ & $21 \%$ & $0.07(0.74)$ & $39.0(11.8)$ \\
\hline & $35-39$ & $13 \%$ & $0.01(0.75)$ & $38.5(11.5)$ \\
\hline & $40-49$ & $6 \%$ & $0(0.73)$ & $37.2(11.6)$ \\
\hline \multicolumn{5}{|c|}{ Family social class at birth } \\
\hline & Advantaged social class & $42 \%$ & $0.12(0.75)$ & $39.8(12.2)$ \\
\hline & Disadvantaged social class & $58 \%$ & $-0.04(0.72)$ & $37.2(10.9)$ \\
\hline \multicolumn{5}{|c|}{ Birth weight (standardized by gest. age) } \\
\hline & Low (Z-score $<-1)$ & $13 \%$ & $-0.03(0.73)$ & $37.8(11.1)$ \\
\hline & Average (Z-score -1 to 1$)$ & $71 \%$ & $0.04(0.74)$ & $38.4(11.6)$ \\
\hline & Heavy (Z-score>1) & $16 \%$ & $0.02(0.71)$ & $38.4(11.5)$ \\
\hline \multicolumn{5}{|c|}{ Head circumference (gest. age-standard) } \\
\hline & Small (Z-score $<-1)$ & $12 \%$ & $-0.02(0.73)$ & $35.7(11.2)$ \\
\hline & Average (Z-score -1 to 1 ) & $75 \%$ & $0.04(0.73)$ & $38.6(11.7)$ \\
\hline & Large $($ Z-score $>1)$ & $13 \%$ & $0.01(0.74)$ & $39.1(11.4)$ \\
\hline
\end{tabular}

Notes. Mean grades represent an average of marks in seven school subjects, each separately standardized with $\bar{x}=0$ and $S=1$ Occupational prestige is measured using a continuous scale ( $\bar{x}=38.3$; range $=6-78$ )

Advantageous socialclass: high/mediate non-manuals, entrepreneurs/farmers, and skilled manuals Disadvantaged class: lower non-manuals, unskilled manuals in production, unskilled manuals in service, house-daughters 


\section{Head circumference at birth, school grades, and occupational prestige}

We began by analysing the effects of birth $\mathrm{HC}$ on school grades (Table 2). In the minimally-adjusted model, small HC was associated with a reduction in mean standardized school grades $(p<0.001)$. Subsequent adjustment for maternal age at birth, birth order, and birth weight resulted in marginal attenuation of the negative effect estimate of small $\mathrm{HC}$ at birth on elementary grades, which remained statistically-significant $(p<0.001)$. A similar pattern was observed after further adjustment for social origin at birth (all estimates from the fully-adjusted model available in supplementary material), where some attenuation in the effect magnitude did occur, but the negative relationship between small $\mathrm{HC}$ at birth and elementary school grades remained statistically significant $(p<0.001)$. Children born to parents of advantaged social class received higher school marks at age 9-10 ( $p<.001)$. No statistically significant effect of larger $\mathrm{HC}$ at birth on school grades at 9-10 years was found in any of the models.

Table 2. Head circumference (HC) at birth and school grades at age 9-10 $(\mathrm{N}=6,024)$ Linear regression, OLS estimates

\begin{tabular}{lccc} 
& \multicolumn{2}{c}{ Regression coefficients } & (95\% confidence intervals) \\
& Model 1 & Model 2 & Model 3 \\
\hline Small HC & $-0.119^{* * *}$ & $-0.102^{* * *}$ & $-0.097^{* * *}$ \\
& $(-0.177,-0.061)$ & $(-0.163,-0.043)$ & $(-0.157,-0.037)$ \\
Average HC & 0 & 0 & 0 \\
& $($ ref $)$ & $($ ref $)$ & (ref) \\
Large HC & 0.031 & 0.035 & 0.031 \\
& $(-0.023,0.084)$ & $(-0.021,0.092)$ & $(-0.025,0.087)$ \\
\hline \multirow{2}{*}{ Advantaged SES at birth } & & & $0.156^{* * *}$ \\
& & & $(0.118,0.193)$ \\
\hline$R^{2}$ & 0.04 & 0.06 & 0.07
\end{tabular}

Notes. ${ }^{* * *} p<0.01, * * p<0.05, * p<0.1$

Robust confidence intervals in parentheses

Model 1: adjusted for sex \& birth cohort

Model 2: adjusted for sex, birth cohort, birth order, maternal age at birth, birth weight (gestational age-standardized)

Model 3: based on model 2, additionally adjusted for social origin at birth (advantaged vs. disadvantaged)

The effects of $\mathrm{HC}$ at birth on lifetime occupational prestige are shown in Table 3 . In a minimallyadjusted model, we found that individuals with small $\mathrm{HC}$ at birth experienced a reduction in prestige score associated with their longest-held adult occupation $(p<0.001)$. This relationship appeared robust to further adjustments for birth characteristics and, eventually, social class at birth (all estimates from the fully-adjusted model are available in supplementary material). Social origin was a statistically significant predictor of occupational prestige score, with advantaged parental social class at birth associated with a high-prestige individual occupation in adulthood $(p<0.001)$. As in the case with school grades, only small $\mathrm{HC}$ at birth was linked with suboptimal outcomes - larger HC did not affect occupational prestige attainment. 
Table 3. Head circumference at birth $(\mathrm{HC})$ and later-life occupational prestige $(\mathrm{N}=6,024)$. Linear regression, OLS estimates

Regression coefficients (95\% confidence intervals)

Outcome: lifetime occupational prestige

$\begin{array}{lll}\text { Model } 1 & \text { Model } 2 & \text { Model } 3\end{array}$

\begin{tabular}{lccc}
\hline Small HC & $-1.805^{* * *}$ & $-1.636^{* *}$ & $-1.551^{* *}$ \\
& $(-2.688,-0.921)$ & $(-2.571,-0.701)$ & $(-2.484,-0.619)$ \\
Average HC & 0 & 0 & 0 \\
& $($ ref $)$ & $($ ref $)$ & (ref) \\
Large HC & -0.355 & -0.434 & -0.499 \\
& $(-1.201,0.490)$ & $(-1.301,0.432)$ & $(-1.361,0.363)$ \\
\hline
\end{tabular}

Advantaged SES at birth

$2.271^{* * *}$

$(1.676,2.877)$

\begin{tabular}{llll}
\hline $\mathrm{R}^{2}$ & 0.06 & 0.09 & 0.10 \\
\hline
\end{tabular}

Notes. $\quad * * * p<0.01, * * p<0.05, * p<0.1$

Robust confidence intervals in parentheses

Model 1: adjusted for sex and birth cohort

Model 2: adjusted for sex, birth cohort, birth order, maternal age at birth, birth weight (gestational age-standardized)

Model 3: based on model 2, additionally adjusted for social origin at birth (advantaged vs. disadvantaged)

\section{Modification by social origin}

To examine interactions between birth $\mathrm{HC}$ and social class with respect to school grades and occupational prestige, we converted a three-level $\mathrm{HC}$ variable (small; average; large) into a binary indicator distinguishing between small head size vs. the rest. We found no evidence of interaction between social class at birth and small $\mathrm{HC}$ when considering elementary school grades $(p=0.14)$ or adult occupational prestige $(p=0.59)$. Furthermore, small $\mathrm{HC}$ at birth was found to be associated with a reduction in grades and prestige amongst children born to parents from either advantageous or disadvantageous social classes (supplementary material, Table A2). Finally, in order to visualize the combined effect of social class and $\mathrm{HC}$ at birth with respect to elementary school grades and occupational prestige, we examined the effects of four indicator variables denoting four possible combinations between social origin (advantaged or not) and $\mathrm{HC}$ at birth (small or not) (Figures 3 \& 4; model estimates in supplementary material, Table $A 3)$. 
Figure 3. Combined effect of parental social class and head circumference $(\mathrm{HC})$ at birth on school grades. Linear regression estimates

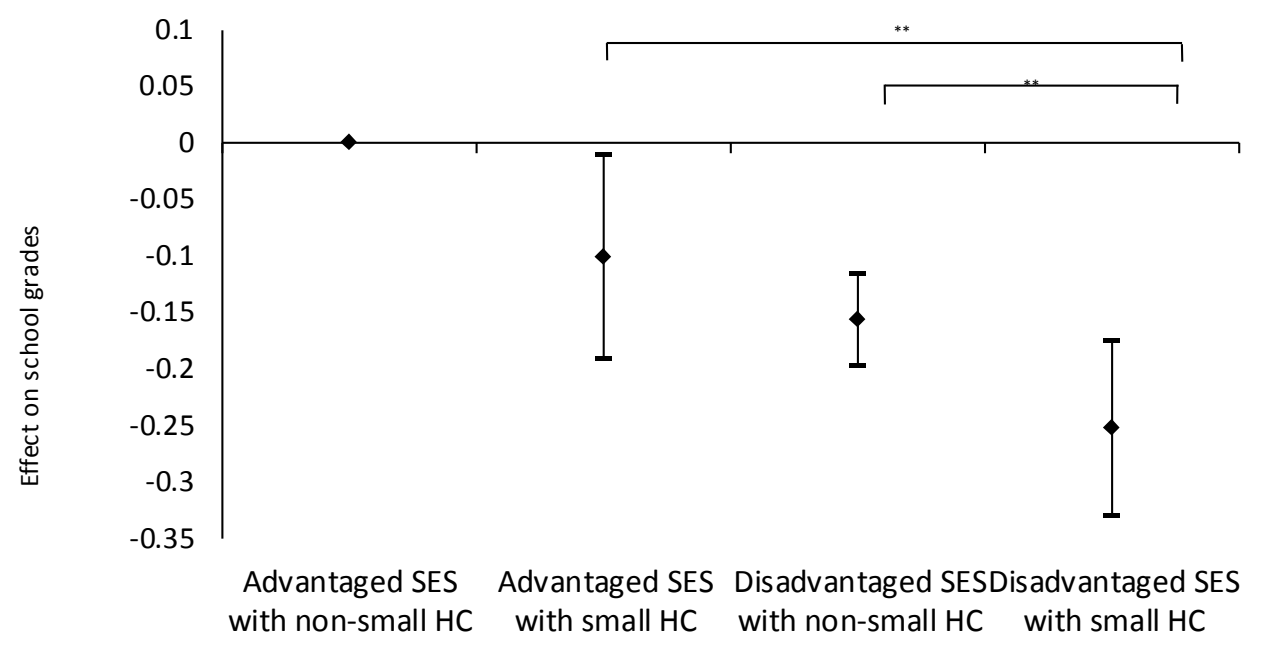

Notes. $\quad 95 \%$ confidence intervals

Adjusted for sex, birth year, birth order, maternal age at birth, birth weight (gestationalage-standardized) Top lines denote statistical difference between estimated parameters.

Estimates available in Table A3 in supplementary material

Figure 4. Combined effects of parental social class and head circumference (HC) at birth on lifetime occupational prestige score. Linear regression estimates

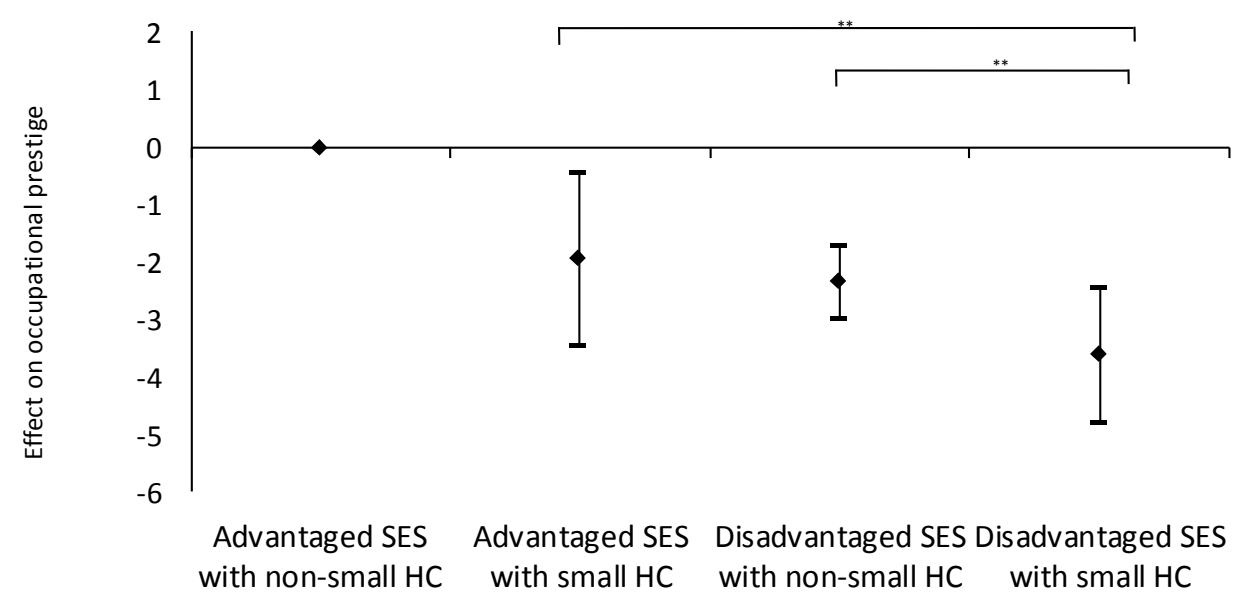

Notes. $\quad 95 \%$ confidence intervals

Adjusted for sex, birth year, birth order, maternal age at birth, birth weight (gestationalage-standardized) Top lines denote statistical difference between estimated parameters.

Estimates available in Table A3 in supplementary material 
As can be seen in Figures 3 and 4, the greatest benefit in terms of school grades, as well as adult occupational prestige was reserved for individuals with non-small head size born to parents of advantaged social class, since any departure from this state reduced both short-term and long-term cognitive and occupational outcomes. The estimated effect of disadvantaged social origin in combination with small HC was statistically different from the effect of disadvantaged social origin with normal head circumference, as well as the effect of advantaged social class with small head size. There was, however, no statistical difference between the latter two estimates, with the effect of advantaged origin with small $\mathrm{HC}$ being statistically similar to the effect of disadvantaged social class with non-small HC.

Mediation analysis: head circumference, school grades, and occupational prestige

Results of the mediation analysis as well as of the main study findings are presented in Figure 5 . With respect to mediation analysis, $\mathrm{HC}$ at birth (modelled as a binary indicator distinguishing between small head size vs. the rest) was related to long-run occupational prestige both directly (adjusted average direct effect: 1.219; $95 \% \mathrm{Cl}:-2.212$ to -0.293 ) and indirectly via elementary school grades (adjusted average causal mediation effect (ACME): $-0.371 ; 95 \% \mathrm{Cl}:-0.579$ to 0.189). The total adjusted effect of birth $\mathrm{HC}$ on adult occupational prestige, including the mediation by elementary school grades was $-1.591(95 \% \mathrm{Cl}:-2.580$ to -0.650$)$. The negative effect estimates imply a strong negative association between small head size and grades, which are positively related to adult occupational prestige. A quarter of the total effect of head size on occupational prestige was mediated by elementary school grades.

Results of the sensitivity analysis indicated that the correlation in omitted variables between the mediation and the outcome models would have to be 0.20 in order for the causal mediation effect to be invalidated. This means an unobserved confounder would have to explain a considerable $20 \%$ of the variance in both school grades and occupational prestige in order for the mediation estimates to become substantively changed.

Figure 5. Mediation of HC effects by school grades and main study findings

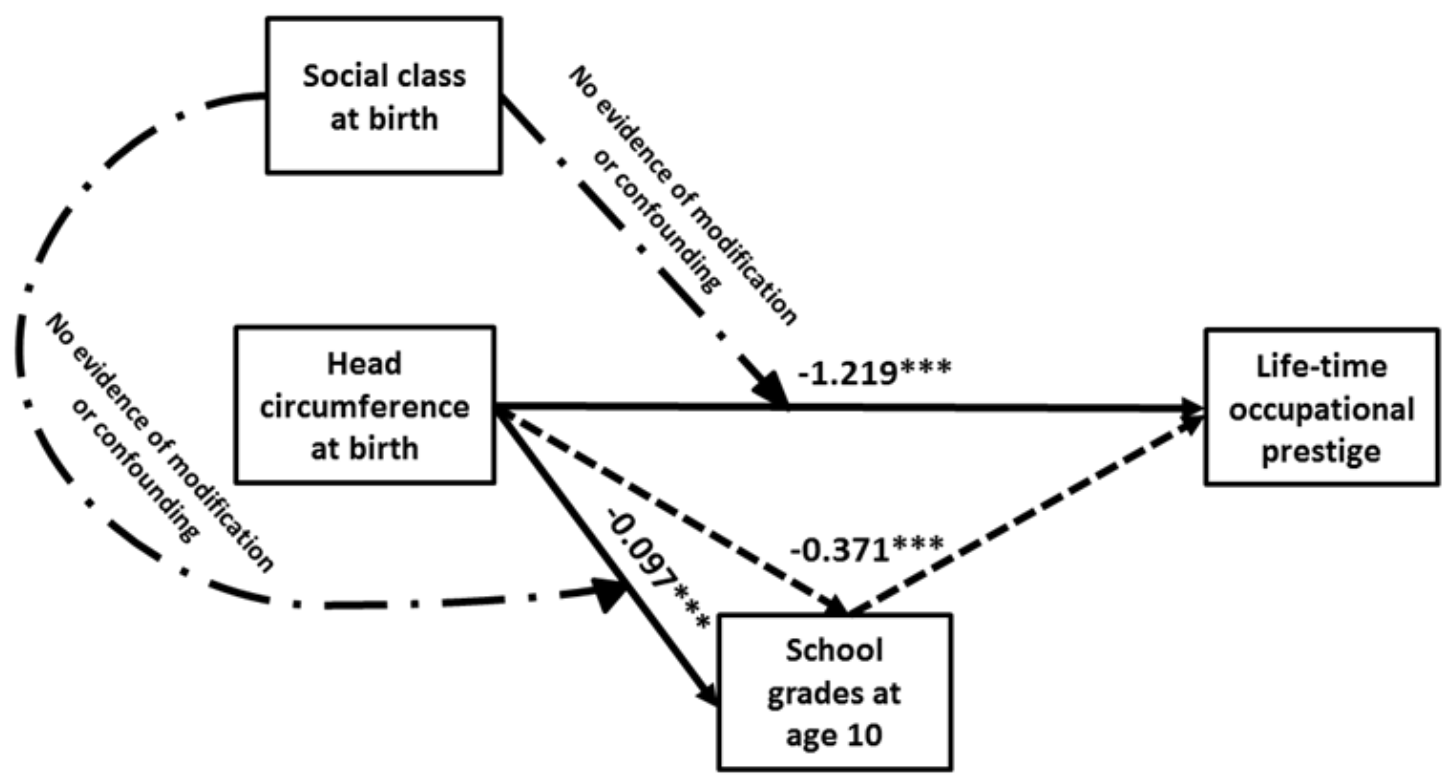

Notes. Estimates of the HC-prestige path and the HC-grades-prestige path (dash) are obtained from the causal mediation analysis: Direct effect: -1.219 (95\% Cl: -2.212 to -0.293 )

Average causal mediation effect (ACME): -0.371 (95\% CI: -0.579 to -0.189 )

Total effect: -1.591 (95\% Cl: -2.580 to -0.650$)$

$\rho$ (correlation of errors between mediator and outcome models) at which ACME will be invalid: 0.20

All models estimated as part of the mediation analysis are adjusted for sex, birth year, birth order, maternal age at birth, birth weight (gestationalage-standardized), and social class at birth

Estimate of the HC-grades path are obtained from a fully-adjusted OLS model with $\mathrm{HC}$ as exposure and school grades as outcome (Table 3)

"No modification/confounding" arrows indicate no evidence of confounding or effect modification of the HC-prestige and HC-school grades pathways by social class of origin (Supplementary material Table A2; Figures 3 \& 4; interaction analysis; SES-adjusted OLS models) 


\section{Discussion}

In this study we examined whether head circumference at birth, an indicator of brain development in utero, was associated with elementary school performance and lifetime occupational prestige. Among individuals born at term, we found that those whose birth $\mathrm{HC}$ fell one standard deviation below the mean experienced reductions in both elementary school grades and lifetime occupational prestige. These findings remained robust after adjustment for confounding due to birth characteristics as well as parental social class at birth. We also established that the association between $\mathrm{HC}$ at birth and short-term cognitive outcomes or lifetime occupational prestige was not subject to effect modification by social class of origin. Finally, using mediation analysis, we demonstrated that $\mathrm{HC}$ at birth was linked to long-run occupational prestige directly, as well as indirectly, by predicting early cognitive ability which then also affected occupational prestige, although the direct effect was the dominant one (Figure 5).

A major strength of this study is that we examined whether the effects of brain size at birth extend beyond such proximate outcomes as school grades in childhood and continue to affect outcomes of later-life occupational achievement and success in the same individuals over the lifecourse. Some (Kunugi, Takei, Murray, Saito, \& Nanko, 1996; Martyn et al., 1996; Raikkonen et al., 2013), but not all (Gale et al., 2003; Zhang et al., 2009), previous studies have reported an association between birth $\mathrm{HC}$ and later cognitive ability. However, instead of assessing cognitive performance in later life, we assessed occupational prestige which has both cognitive (the correlation between intelligence and occupational attainment is about .40 (Strenze, 2007)) and social prerequisites, and which also can be viewed as a measure of lifetime status achievement. It has been reported previously that head circumference at birth, together with other birth outcomes, is associated with cognitive performance and cognitive change in adult life (Raikkonen et al., 2013). Our findings extend this literature by demonstrating that the negative effects of small $\mathrm{HC}$ at birth are discernible in childhood, and linger on to also affect status attainment in adulthood. Our second contribution is the demonstration that the link between birth HC and adult status attainment is not only present, but is also primarily direct and only somewhat mediated by the short-term effect of birth HC on childhood school grades, which then help shape adult occupational outcomes.

Our results are also consistent with previous literature reporting an association between foetal brain development and early-life cognitive ability (Broekman et al., 2009; Veena et al., 2010), although we used information on school grades at age 9-10 in the absence of explicitly-measured IQ. The reasons why some infants are delivered with small HC are manifold. Maternal under-nutrition is one of the primary causes of small birth head circumference, although both genetic (Toga \& Thompson, 2005) and various environmental factors are also implicated (Doberczak, Thornton, Bernstein, \& Kandall, 1987; Källén, 2000). A model of foetal programming predicts that in-utero development might be constrained in order to maximize overall survival chances in the turbulent environment (Gluckman \& Hanson, 2004). Consequently, investments in repair mechanisms or reserve tissues, such as excess neurons or synaptic capacity in the brain are likely to be reduced (Broekman et al., 2009). While the brain-sparing hypothesis suggests that brain development ought to be shielded from adjustments aimed at postnatal fitness advantage in hostile environments (Godfrey \& Barker, 2001), evidence suggests that those endocrine mechanisms that restrict foetal growth can also compromise neural development (Goland et al., 1993; Meaney, Szyf, \& Seckl, 2007; Schneider, Moore, Kraemer, Roberts, \& DeJesus, 2002; Seckl \& Holmes, 2007; Winick \& Noble, 1966). Programming of the hypothalamic-pituitary-adrenal (HPA) axis could play an important role in this process, with the HPA modification being an intermediate step between limited nutrition, foetal maturation, and postnatal pathophysiology (Seckl \& Holmes, 2007). Following the modification of the HPA, anabolic effects of the growth hormone are antagonized, resulting in changes in organ development and maturation, including the brain (Broekman et al., 2009). Therefore, the link between small head size at birth and cognitive outcomes could arise not only due to growth restriction that reduces brain volume, but also due to the relationship between the modifiers of foetal growth restriction (changes in the expression of the HPA axis) and postnatal cognitive outcomes. 
It has been shown previously (Gale et al., 2006) that the effects of birth head circumference on childhood intelligence are weakened when later-life measurements of childhood head size are used instead. Postnatal estimates of head circumference might be more precise than measurements collected during delivery. Others, however, have indicated that both prenatal and postnatal measurements of head circumference can predict cognitive abilities among children at 56 months of age (Heinonen et al., 2008). We did not have access to later estimates of head size and, therefore, cannot provide cues on the relative importance of different critical periods during brain development. Nonetheless, a reduction in the effect size of birth head size in favor of subsequently-measured estimates of head circumference, as reported by some, should indicate that a common causal pathway connects head size at birth, postnatal head growth, and childhood cognitive function (Veena et al., 2010).

Our study also demonstrated that the relationship between birth $\mathrm{HC}$ and school performance in childhood or occupational outcomes in adulthood is not readily explained by confounding or effect modification by social class of origin. We reported only additive effects of birth $\mathrm{HC}$ and social origin with respect to childhood grades and lifetime prestige. Essentially, disadvantaged social origin and small birth $\mathrm{HC}$ each imply a reduction in short-term as well as long-term cognitive and human capital outcomes. A combination of these disadvantages is associated with a proportionally greater reduction in the outcomes considered, although birth $\mathrm{HC}$ is detrimental irrespective of the social class an individual may have been born into. Strengthened by no evidence of an interaction between social origin and $\mathrm{HC}$, we conclude that social origin and birth HC mainly act independently in shaping childhood school grades as well as general lifetime attainment. A previous study found that social class at birth modified the relationship between gestational age and early school performance (Gisselmann et al., 2011). On the other hand, no evidence of effect modification by social origin was reported in two previous studies linking birth weight and childhood cognitive outcomes (Jefferis et al., 2002; Matte et al., 2001) and our findings are consistent with these results, although we also report no modification when a distant outcome is considered, something not shown to date.
Our finding of no effect modification by social origin is relevant to our earlier discussion about the underlying causes of small $\mathrm{HC}$ at birth. Maternal under-nutrition is undoubtedly one of the primary causes of small birth $\mathrm{HC}$, and it is also likely related to socioeconomic opportunities. We reported here, however, that infants of affluent and disadvantaged parents are equally vulnerable with respect to childhood school grades and adult occupational prestige if born with small HC. While inadequate nutrition during pregnancy might apply to disadvantaged mothers, it is unlikely to be a decisive factor determining the birth outcomes of children born to affluent parents. Thus, it has been hypothesized previously that in high-SES families with abundant access to economic resources, occurrence of low birth-weight is likely underpinned by psychosocial factors or behavioural characteristics (Foster et al., 2000). In addition to nutrition, previous research has identified maternal stress (Mulder et al., 2002) and pesticide exposure (Berkowitz et al., 2004) as correlates of small HC at birth and these factors might be at work here, at least when affluent families with small $\mathrm{HC}$ deliveries are considered.

Finally, we employed mediation analysis to examine the extent to which the link between head size at birth and adult occupational prestige was direct, or rather mediated by early cognitive ability at age 10. We demonstrated that a quarter of the association between head size at birth and occupational prestige was mediated by elementary school performance, with the bulk of the effect being due to a direct link between birth $\mathrm{HC}$ and occupational attainment. To our knowledge, ours is the first study that has attempted such analysis. A previous study tested whether the association between birth weight and psychological distress at ages $45-51$ was mediated by IQ at age 7, and found no evidence of mediation by early-life IQ (Wiles, Peters, Leon, \& Lewis, 2005). Although the direct effect was found to be a predominant one in our study as well, we also report that a rather sizeable quarter of the total link between birth $\mathrm{HC}$ and adult occupational prestige was due to mediation by early school performance.

\section{Limitations}

Since we had no direct information on childhood cognitive ability, we instead examined the relationship between birth $\mathrm{HC}$ and school grades at 
age 10. Childhood cognitive ability and school grades are correlated ( $r \approx .5)$ (Gustafsson \& Reuterberg, 2000; Neisser et al., 1996; Rosander et al., 2011) and grades are also associated with other indicators of low cognitive ability such as being held back in school or having a recognized learning difficulty (Goodman \& Koupil, 2009). Moreover, our factor analysis of raw school grades indicated that a single latent factor explained most of the variation in school performance, much the same way general mental ability (g) underlies intelligence test scores.

We chose the Standard International Occupational Prestige Scale over the more commonly-used International Socioeconomic Index of Occupational Status (ISEI) which ranks occupations in relation to their average education and income levels to show how occupational structure influences the ability to convert education into income. Although an effective tool at capturing formal attributes of occupations, ISEI is less suitable for this particular cohort which largely refrained from transitioning to tertiary education. Furthermore, ISEI was developed for occupations of full-time, male adults. Estimates for women were made, but with data for men working in predominantly female occupations (Rose, 2005).

About $30 \%$ of the eligible cohort members were excluded from the final analysis. Loss of eligible individuals from the analysis population was mainly due to missing data on school grades ( $55 \%$ of the total with missing data). School grades were more likely to have been untraced among children of the highest socio-economic background who were more prone to attend private schools where archival coverage was weaker. Furthermore, we excluded 687 individuals for whom occupational information could not be traced. These were almost exclusively women, whom we suspected to be housewives. In a sensitivity analysis, we classified women with missing occupational information as employed as "housekeepers and other workers" and assigned them a prestige score associated with this paid position. Substantive results remained unchanged and we decided to exclude the group with missing occupational data to avoid misclassification of exposure. We also examined differences in educational attainment and found only minor discrepancies between the excluded and the study population (incomplete elementary education: $46 \%$ vs. $49 \%$; completed elementary: $39 \%$ vs. $35 \%$; beyond completed elementary: $15 \%$ vs. $16 \%$, respectively). It is, therefore, unlikely that considerable bias was introduced when adjustments for missing data were made.

\section{Conclusions}

Individuals with small head circumference at birth experienced reductions in childhood school grades as well as later-life occupational prestige. This relationship was not due to confounding or effect modification by social class of origin. Further, $\mathrm{HC}$ at birth impacted long-run occupational prestige mainly directly, but also indirectly, by influencing school grades at age 9-10, which in turn affected occupational prestige. Our results add to the evidence on the importance of foetal brain growth for later life educational and social outcomes.

\section{Acknowledgements}

The Uppsala Birth Cohort Multigenerational Study is supported by the Swedish Research Council (20135104 and 2013-5474) and by the Swedish Research Council for Health, Working Life and Welfare (2013-1084 and 2014-2693). In addition, individually directed grants from the Swedish Research Council supported the research (521-2007-3020 [AH, SD]; 2008-7503 [SD, KS]), as did grants from the Swedish Research Council for Health, Working Life and Welfare (2007-0767 [AH, SD]). HXW was also supported by the Swedish Foundation for Health Care Sciences and Allergy Research, the Stohnes Foundation, the Konung Gustaf V:s och Drottning Victorias Frimurare Foundation, Swedish Brain Power, and the Board of Research at Karolinska Institutet, and IK was supported by the Swedish Research Council for Health, Working Life and Welfare (2006-1518). 


\section{References}

Berkowitz, G. S., Wetmur, J. G., Birman-Deych, E., Obel, J., Lapinski, R. H., Godbold, J. H., Holzman, I. R., \& Wolff, M. S. (2004). In utero pesticide exposure, maternal paraoxonase activity, and head circumference. Environmental Health Perspectives, 112(3), 388-391. http://dx.doi.org/10.1289/ehp.6414

Black, S. E., Devereux, P. J., \& Salvanes, K. G. (2007). From the cradle to the labor market? The effect of birth weight on adult outcomes. The Quarterly Journal of Economics, 122(1), 409-439. http://dx.doi.org/10.1162/qjec.122.1.409

Bradley, R. H., \& Corwyn, R. F. (2002). Socioeconomic status and child development. Annual Review of Psychology, 53(1), 371-399. http://dx.doi.org/10.1146/annurev.psych.53.100901.135233

Broekman, B. F., Chan, Y. H., Chong, Y. S., Quek, S. C., Fung, D., Low, Y. L., Ooi, Y. P., Gluckman, P. D., Meaney, M. J., Wong, T. Y., \& Saw, S. M. (2009). The influence of birth size on intelligence in healthy children. Pediatrics, 123(6), e1011-1016. http://dx.doi.org/10.1542/peds.2008-3344

Chitty, L. S., Altman, D. G., Henderson, A., \& Campbell, S. (1994). Charts of fetal size: 2. Head measurements*. British Journal of Obstetrics and Gynaecology: An International Journal of Obstetrics \& Gynaecology, 101(1), 35-43. http://dx.doi.org/10.1111/j.1471-0528.1994.tb13007.x

Cooke, R. W. I., Lucas, A., Yudkin, P. L. N., \& Pryse-Davies, J. (1977). Head circumference as an index of brain weight in the fetus and newborn. Early Human Development, 1(2), 145-149. http://dx.doi.org/10.1016/0378-3782(77)90015-9

Deary, I. J., Taylor, M. D., Hart, C. L., Wilson, V., Smith, G. D., Blane, D., \& Starr, J. M. (2005). Intergenerational social mobility and mid-life status attainment: influences of childhood intelligence, childhood social factors, and education. Intelligence, 33(5), 455-472. http://dx.doi.org/10.1016/j.intell.2005.06.003

Doberczak, T. M., Thornton, J. C., Bernstein, J., \& Kandall, S. R. (1987). Impact of maternal drug dependency on birth weight and head circumference of offspring. American Journal of Diseases of Children, 141(11), 1163-1167.

Duncan, G. J., Brooks-Gunn, J., \& Klebanov, P. K. (1994). Economic deprivation and early childhood development. Child Development, 65(2), 296-318. http://dx.doi.org/10.2307/1131385

Fischer, C. S., Hout, M., Jankowski, M. S., Lucas, S. R., Swidler, A., \& Voss, K. (1996). Inequality by design: Princeton University Press Princeton, NJ.

Foster, H. W., Wu, L., Bracken, M. B., Semenya, K., Thomas, J., \& Thomas, J. (2000). Intergenerational effects of high socioeconomic status on low birthweight and preterm birth in African Americans. Journal of the National Medical Association, 92(5), 213-221.

Gale, C. R., O'Callaghan, F. J., Bredow, M., Martyn, C. N., \& the Avon Longitudinal Study of Parents and Children Study Team (2006). The influence of head growth in fetal life, infancy, and childhood on intelligence at the ages of 4 and 8 years. Pediatrics, 118(4), 1486-1492. http://dx.doi.org/10.1542/peds.2005-2629

Gale, C. R., Walton, S., \& Martyn, C. N. (2003). Foetal and postnatal head growth and risk of cognitive decline in old age. Brain, 126(10), 2273-2278. http://dx.doi.org/10.1093/brain/awg225

Ganzeboom, H. B. G., \& Treiman, D. J. (1996). Internationally comparable measures of occupational status for the 1988 international standard classification of occupations. Social Science Research, 25, 201239. http://dx.doi.org/10.1006/ssre.1996.0010

Gisselmann, M., Koupil, I., \& De Stavola, B. L. (2011). The combined influence of parental education and preterm birth on school performance. Journal of Epidemiology \& Community Health, 65(9), 764-769. http://dx.doi.org/10.1136/jech.2009.105569

Gluckman, P. D., \& Hanson, M. A. (2004). Living with the past: evolution, development, and patterns of disease. Science, 305(5691), 1733-1736. http://dx.doi.org/10.1126/science.1095292

Godfrey, K. M., \& Barker, D. J. (2001). Fetal programming and adult health. Public Health Nutrition, 4(2B; SPI), 611-624.

Goland, R., Jozak, S., Warren, W., Conwell, I., Stark, R., \& Tropper, P. (1993). Elevated levels of umbilical cord plasma corticotropin-releasing hormone in growth-retarded fetuses. Journal of Clinical Endocrinology \& Metabolism, 77(5), 1174-1179.

Goodman, A., Gisselmann, M. D., \& Koupil, I. (2010). Birth outcomes and early-life social characteristics predict unequal educational outcomes across the life course and across generations. Longitudinal and Life Course Studies, 1(4), 317-338.

Goodman, A., \& Koupil, I. (2009). Social and biological determinants of reproductive success in Swedish males and females. Evolution and Human Behavior, 30(5), 329-341. http://dx.doi.org/10.1016/j.evolhumbehav.2009.03.007

Goodman, A., \& Koupil, I. (2012). Low fertility increases descendant socioeconomic position but reduces long-term fitness in a modern post-industrial society. Proceedings of the Royal Society B, 279(1746), 4342-4351.. 
Gustafsson, J.-E., \& Reuterberg, S.-E. (2000). Metodproblem vid studier av Högskoleprovets prognosförmåga - och deras lösning. [Methodological problems in the study of the Swedish scholastic apitude test and the solution]. Pedagogisk Forskning i Sverige, 5(4), 273-283.

Hackman, D. A., Farah, M. J., \& Meaney, M. J. (2010). Socioeconomic status and the brain: mechanistic insights from human and animal research. Nature Reviews Neuroscience, 11(9), 651-659. http://dx.doi.org/10.1038/nrn2897

Härkönen, J., \& Bihagen, E. (2011). Occupational attainment and career progress in Sweden. European Societies, 13(3), 451-479. http://dx.doi.org/10.1080/14616696.2011.568261

Heinonen, K., Räikkönen, K., Pesonen, A.-K., Kajantie, E., Andersson, S., Eriksson, J. G., Niemelä, A., Vartia, T., Peltola, J., \& Lano, A. (2008). Prenatal and postnatal growth and cognitive abilities at 56 months of age: a longitudinal study of infants born at term. Pediatrics, 121(5), e1325-e1333. http://dx.doi.org/10.1542/peds.2007-1172

Hicks, R., \& Tingley, D. (2011). Causal mediation analysis. The Stata Journal, 11(4), 605-619.

Holland, D., Chang, L., Ernst, T. M., Curran, M., Buchthal, S. D., Alicata, D., Skranes, J., Johansen, H., Hernandez, A., \& Yamakawa, R. (2014). Structural growth trajectories and rates of change in the first 3 months of infant brain development. Journal of the American Medical Association: Neurology, 71(10), 1266-1274.

Imai, K., Keele, L., \& Tingley, D. (2010). A general approach to causal mediation analysis. Psychological Methods, 15(4), 309. http://dx.doi.org/10.1037/a0020761

Imai, K., Keele, L., \& Yamamoto, T. (2010). Identification, inference and sensitivity analysis for causal mediation effects. Statistical Science, 25(1), 51-71. http://dx.doi.org/10.1214/10-STS321

Jefferis, B. J., Power, C., \& Hertzman, C. (2002). Birth weight, childhood socioeconomic environment, and cognitive development in the 1958 British birth cohort study. British Medical Journal, 325(7359), 305. http://dx.doi.org/10.1136/bmj.325.7359.305

Källén, K. (2000). Maternal smoking during pregnancy and infant head circumference at birth. Early Human Development, 58(3), 197-204. http://dx.doi.org/10.1016/S0378-3782(00)00077-3

Koupil, I. (2007). The Uppsala studies on developmental origins of health and disease. Journal of Internal Medicine, 261(5), 426-436. http://dx.doi.org/10.1111/j.1365-2796.2007.01799.x

Kunugi, H., Takei, N., Murray, R. M., Saito, K., \& Nanko, S. (1996). Small head circumference at birth in schizophrenia. Schizophrenia Research, 20(1), 165-170. http://dx.doi.org/10.1016/09209964(96)85526-5

Lindley, A. A., Benson, J. E., Grimes, C., Cole, T. M., \& Herman, A. A. (1999). The relationship in neonates between clinically measured head circumference and brain volume estimated from head CT-scans. Early Human Development, 56(1), 17-29. http://dx.doi.org/10.1016/S0378-3782(99)00033-X

Martyn, C. N., Gale, C. R., Sayer, A. A., \& Fall, C. (1996). Growth in utero and cognitive function in adult life: follow up study of people born between 1920 and 1943. British Medical Journal, 312(7043), 13931396. http://dx.doi.org/10.1136/bmj.312.7043.1393a

Matte, T. D., Bresnahan, M., Begg, M. D., \& Susser, E. (2001). Influence of variation in birth weight within normal range and within sibships on IQ at age 7 years: cohort study. British Medical Journal, 323(7308), 310-314. http://dx.doi.org/10.1136/bmj.323.7308.310

Meaney, M. J., Szyf, M., \& Seckl, J. R. (2007). Epigenetic mechanisms of perinatal programming of hypothalamic-pituitary-adrenal function and health. Trends in Molecular Medicine, 13(7), 269-277. http://dx.doi.org/10.1016/j.molmed.2007.05.003

Mishra, G. D., Chiesa, F., Goodman, A., De Stavola, B., \& Koupil, I. (2013). Socio-economic position over the life course and all-cause, and circulatory diseases mortality at age 50-87 years: results from a Swedish birth cohort. European Journal of Epidemiology, 28(2), 139-147. http://dx.doi.org/10.1007/s10654-013-9777-z

Moster, D., Lie, R. T., \& Markestad, T. (2008). Long-term medical and social consequences of preterm birth. New England Journal of Medicine, 359(3), 262-273. http://dx.doi.org/10.1056/NEJMoa0706475

Mulder, E., Robles de Medina, P., Huizink, A., Van den Bergh, B., Buitelaar, J., \& Visser, G. (2002). Prenatal maternal stress: effects on pregnancy and the (unborn) child. Early Human Development, 70(1), 314. http://dx.doi.org/10.1016/S0378-3782(02)00075-0

Neisser, U., Boodoo, G., Bouchard, T., Boykin, W., Brody, N., Ceci, S., Halpern, D., Loehlin, J., Perloff, R., Sternberg, R., \& Urbina, S. (1996). Intelligence: knowns and unknowns. American Psychologist, 51(2). 77-101. http://dx.doi.org/10.1037/0003-066X.51.2.77

Raikkonen, K., Kajantie, E., Pesonen, A.-K., Heinonen, K., Alastalo, H., Leskinen, J. T., Nyman, K., Henriksson, M., Lahti, J., \& Lahti, M. (2013). Early life origins of cognitive decline: findings in elderly men in the Helsinki birth cohort study. PloS one, 8(1), e54707. http://dx.doi.org/10.1371/journal.pone.0054707

Richards, M., Hardy, R., Kuh, D., \& Wadsworth, M. E. (2001). Birth weight and cognitive function in the British 1946 birth cohort: longitudinal population based study. British Medical Journal, 322(7280), 199-203. http://dx.doi.org/10.1136/bmj.322.7280.199 
Richards, M., Hardy, R., Kuh, D., \& Wadsworth, M. E. (2002). Birthweight, postnatal growth and cognitive function in a national UK birth cohort. International Journal of Epidemiology, 31(2), 342-348. http://dx.doi.org/10.1093/ije/31.2.342

Rosander, P., Bäckström, M., \& Stenberg, G. (2011). Personality traits and general intelligence as predictors of academic performance: a structural equation modelling approach. Learning and Individual Differences, 21(5), 590-596. http://dx.doi.org/10.1016/j.lindif.2011.04.004

Rose, D. (2005). Socio-economic classifications: classes and scales, measurement and theories. Paper presented at the First Conference of the European Survey Research Association, Pompeu Fabra University, Barcelona.

Schneider, M. L., Moore, C. F., Kraemer, G. W., Roberts, A. D., \& DeJesus, O. T. (2002). The impact of prenatal stress, fetal alcohol exposure, or both on development: perspectives from a primate model. Psychoneuroendocrinology, 27(1-2), 285-298. http://dx.doi.org/10.1016/S0306-4530(01)00050-6

Seckl, J. R., \& Holmes, M. C. (2007). Mechanisms of disease: glucocorticoids, their placental metabolism and fetal 'programming' of adult pathophysiology. Nature Clinical Practice Endocrinology and Metabolism, 3(6), 479-488. http://dx.doi.org/10.1038/ncpendmet0515

Silva, A., Metha, Z., \& O'Callaghan, F. J. (2006). The relative effect of size at birth, postnatal growth and social factors on cognitive function in late childhood. Annals of Epidemiology, 16(6), 469-476. http://dx.doi.org/10.1016/j.annepidem.2005.06.056

SOU. (1942). Betänkande med utredning och förslag angående betygssättningen [Official report and proposal for elementary school grading]. Stockholm: SOU.

Strenze, T. (2007). Intelligence and socioeconomic success: a meta-analytic review of longitudinal research. Intelligence, 35(5), 401-426. http://dx.doi.org/10.1016/j.intell.2006.09.004

Toga, A. W., \& Thompson, P. M. (2005). Genetics of brain structure and intelligence. Annual Review of Neuroscience, 28, 1-23. http://dx.doi.org/10.1146/annurev.neuro.28.061604.135655

Veena, S. R., Krishnaveni, G. V., Wills, A. K., Kurpad, A. V., Muthayya, S., Hill, J. C., Karat, S. C., Nagarajaiah, K. K., Fall, C. H., \& Srinivasan, K. (2010). Association of birthweight and head circumference at birth to cognitive performance in 9-to 10-year-old children in south India: prospective birth cohort study. Pediatric Research, 67(4), 424-429. http://dx.doi.org/10.1203/PDR.0b013e3181d00b45

Webb, S. J., Monk, C. S., \& Nelson, C. A. (2001). Mechanisms of postnatal neurobiological development: implications for human development. Developmental Neuropsychology, 19(2), 147-171. http://dx.doi.org/10.1207/S15326942DN1902 2

Wiles, N. J., Peters, T. J., Leon, D. A., \& Lewis, G. (2005). Birth weight and psychological distress at age 45-51 years: results from the Aberdeen Children of the 1950s cohort study. British Journal of Psychiatry, 187(1), 21-28. http://dx.doi.org/10.1192/bjp.187.1.21

Winick, M., \& Noble, A. (1966). Cellular response in rats during malnutrition at various ages. The Journal of Nutrition, 89(3), 300-306.

Zhang, Z. X., Plassman, B. L., Xu, Q., Zahner, G. E., Wu, B., Gai, M. Y., Wen, H. B., Chen, X., Gao, S., Hu, D., Xiao, X. H., Shen, Y., Liu, A. M., \& Xu, T. (2009). Lifespan influences on mid- to late-life cognitive function in a Chinese birth cohort. Neurology, 73(3), 186-194. http://dx.doi.org/10.1212/WNL.0b013e3181ae7c90 